\title{
Aortokoroner bypass cerrahisi uygulanan olgularda EuroSCORE ve STS risk parametrelerinin karşılaştırılması
}

\author{
Comparison of EuroSCORE and STS risk parameters in patients performed with coronary \\ artery bypass surgery
}

\author{
Mehmet Salih Aydın, Mustafa Göz, Abdussemet Hazar, Aydemir Koçarslan
}

\section{ÖZET}

Amaç: Bu çalışmada izole koroner bypass olgularında operatif mortaliteyi öngörmede EuroSCORE ve STS risk belirleme sistemlerinin klinik uygulanabilirliğinin karşılaştırılması amaçlandı.

Yöntemler: Nisan 2005-Mart 2009 tarihleri arasında opere edilen 182 izole koroner bypass olgusunun tüm risk faktörleri, EuroSCORE ve STS risk belirleme sistemlerine göre prospektif olarak kaydedildi. Öngörülen ve gerçekleşen mortalite oranları her risk skoru sistemi için karşılaştırıldı.

Bulgular: Operatif mortalite, 24 hasta ile \%13,2 olarak bulundu. EuroSCORE için beklenen mortalite $\% 4,71 \pm 4,9$

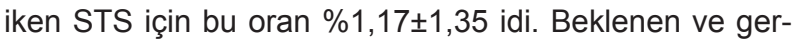
çekleşen mortalite oranları arasında fark bulunamadı. EuroSCORE için ROC Curve altında kalan alan 0,712, STS için 0,727 olarak hesaplandı.

Sonuç: Her iki sistemde mortaliteyi öngörme kuvveti açısından, çalışmamızda yeterli olarak bulunmuştur. STS'nin operatif mortalite yanında oluşabilecek morbidite hakkında da bilgi vermesi ek bir avantaj olarak görülebilmesine rağmen çalışmamızda yeterli bulunmamıştır. Sonuç olarak ülkemiz popülasyonu için yeni risk skorlarına ihtiyaç vardır.

Anahtar kelimeler: Aortokoroner bypas, cerrahi, STS, EuroSCORE, risk

\begin{abstract}
Objective: To compare the feasibility of the EuroSCORE and The Society of Thoracic Surgeons risk scoring systems for predicting the surgical mortality of isolated coronary artery bypass surgery patients.
\end{abstract}

Methods: The risk scoring of 148 patients who were operated on between April 2005 and March 2009 was performed prospectively according to the EuroSCORE and STS risk scoring systems. The predicted and observed mortality rates according to each scoring system were compared.

Results: Hospital mortality was $13.2 \%$ (24 patients). The predicted mortality rate according to EuroSCORE was $4.71 \pm 4.9 \%$, whereas it was $1.17 \pm 1.35 \%$ for STS. There were no significant differences between predicted and observed mortality rates according to either scoring system. The area under the ROC curve was 0.712 for EuroSCORE and was 0.727 for STS.

Conclusion: Both scoring systems were efficient for predicting mortality rates for our study. It is an advantage of STS that it also gives valuable information about morbidity but for our not found satisfactory. In conclusion new risks scores for our country's population are needed.

Key words: Aorta-coronary bypass, surgery, STS, EurOSCORE, risk 


\section{GíRIŞ}

Açık kalp cerrahisinde risk değerlendirmesi cerrahi ekibe operasyon öncesi morbidite ve mortalite oranlarını bilme şansını sağlar. Hastalara ve yakınlarının da ameliyat öncesi bu bilgiye ihtiyaçları olduğu kadar hakları da vardır. Bu iki önemli neden kalp cerrahisinde risk skorlama sistemi kullanılması ihtiyacını doğurmuştur.

Risk değerlendirmesi sağlık standartlarının incelenmesi ile başlamıştır. İlk olarak gözlemleyen Florance Nightingale olmuştur. Nightingale hastane dışında ve taşrada tedavi görenlerin mortalitesinin daha düşük olduğunu gözlemlemiştir. $\mathrm{Bu}$ gözlem 1şığında kalite yönetimi konusunda gerekli adımlar1 atmıştır. Ernest Amory Codman ise 1900 yılların başında anestezi alan hastaların komplikasyon oranlarını karşılaştırarak çıkan sonuçları bilim dünyası ile paylaşmıştır [1].

Kalp cerrahisinde kullanılan ilk skorlama sistemi 1989 yılında yayınlanan Parsonnet skorlama sistemidir [2]. Cleveland Clinic skorlama sistemi de hem mortalite hem morbidite için geliştirilmiş ve 1992 yılında yayınlanmıştır [3]. The Society of Thoracic Surgeons National Database (STS) risk skorlama sistemi 1994 yılında, EuroSCORE risk skorlama sistemi ise 19030 hastada prospektif olarak yapılan ve beklenen mortalite için geliştirilmiş en yeni risk skorlama sistemi olup sonuçları 1999 yılında yayınlanmıştır [4].

\section{YÖNTEMLER}

\section{Hasta Seçimi}

Bu çalışmaya Nisan 2005 ile Mart 2009 tarihinde ardış1k, on-pump, off-pump koroner bypass ameliyatı olan 311 hasta dahil edildi. Çalışma ek kalp operasyonu olmayan izole koroner bypass operasyonu olan 182 hastanın verileri üzerinden yapıldı. 129 hasta ek kalp operasyonu olduğundan çalışma dışına çıkarıldı. Çalışma Harran Üniversitesi Tıp Fakültesi Etik komitesi tarafından onay alınarak yapılmıştır.

\section{İstatistik}

Hastaların verileri "www.sts.org" ve 'www.euroscore.org" adresinden hesaplama araçlarına girilerek çıkan veriler "SPSS 16.0 for Windows" ortamına aktarıldı. Çalışmada elde edilen tüm veriler istatistiki olarak değerlendirilirken SPSS 16.0 for Windows programı kullanıldı. Verilerin minimum ve maksimal değerleri, ortalama \pm standart sapmaları hesaplanarak, yüzde cinsinden oran olarak ifade edildi. Verilerilerin analizinde ise regresyon analizi, Mann Whitney U testi, Receiver Operating Characteristic Curve (ROC) ve Pearson $\chi^{2}$ testi kullanıld1. $\mathrm{p}<$ 0.05 'den değerleri istatiksel olarak anlamlı kabul edildi.

\section{BULGULAR}

Çalışmaya dahil edilen 182 hastanın \%65,4'ü erkek \%34,6'ü kadındı (Tablo 1). Ortalama damar hastalı$\breve{g} 1$ say1s1 $2,6 \pm 0,65$ olup, yapilan koroner arter bypass

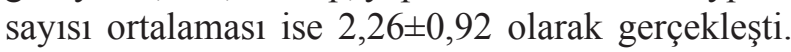
Olguların \%15,9'u hastaneye yatırıldıktan sonra ilk 24 saat içinde operasyona alındı. Olguların \%56,6 atan kalpte, \%43,4 kardiyopulmoner bypass altında opere edildi (Tablo 2). Ortalama kardiyopulmoner bypass süresi $81,24 \pm 35,19$, ortalama kros klemp zamanı 41,26 $\pm 16,49$ olarak gerçekleşti (Tablo 3). Olguların \%15,4'ünde düşük kardiyak debi gelişti. 32 olguda postoperatif aritmi, 10 hastada nörolojik olay gelişti. 6 hasta kanama revizyonuna alınd. Mortalite 24 hasta ile \%13,2 olarak gerçekleşti (Tablo 4).

Çalışmanın numerik olarak girilen verilerinin istatistiksel değerlendirilmesinde; yaş ortalamaS1 artışı ile EF oranı azalması mortalite oranındaki artışa direk etki etmektedir. Hastalıklı damar sayısı arttıkça mortalite artmaktadır $(\mathrm{p}<0,05)$. Buna karşın, greft sayısı arttıkça mortalite artmamaktadır $(p=0,17)$. Lojistik EuroSCORE değeri yükseldikçe mortalite artmakta $(\mathrm{p}=0,01)$, STS mortalite yüzdesi arttıkça mortalite artmaktadır $(\mathrm{p}=0,001)$.

Diğer verilerle yapılan istatistikte cinsiyetin mortalite üzerine etkisinin olmadığı görüldü $(p=0,215)$. sol ana koroner hastalığının olması mortalite açısından anlamlı bulunmamasına rağmen, NYHA Klas III-IV olan hastalarda mortalite anlamlı derecede yüksek tespit edildi ( $\mathrm{p}=0,001)$. Buna karşın NYHA Klas II ve altı olan hastalarda mortalite anlamlı derecede düşük bulundu $(\mathrm{p}=0,001)$. Diyabet, hipertansiyon, periferik arter hastalığ 1 , kronik akciğer hastalığ kullanımı, renal disfonksiyon, dislipidemi varlığı, 
geçirilmiş Mİ ve preoperatif aritmi, mortaliteyi etkileyen faktör olarak tespit edilmedi.

Mortalite gerçekleşen ve gerçekleşmeyen hastalar Mann-Whitney U testi ile karşılaştırıldı EuroSCORE ve STS risk parametreleri anlamlı bulundu (Tablo 5). EuroSCORE ve STS risk sinıflamalarının mortaliteyi öngörme yeteneği "Receiver Operating Characteristic Curve" (ROC eğrisi) analiz yöntemi kullanılarak araştırıldı. ROC eğrisi altında kalan alan 0,7 altında ise anlamsız, 0,7-0,8 arasinda ise kabul edilebilir, 0,8-0,.9 arasında çok iyi ve 0,9 üzerinde ise mükemmel olarak değerlendirildi. Beklenen mortalite Euroscore için 4,71 $\pm 4,9$, STS için $1,17 \pm 1,35$ olmasina rağmen, mortalite 24 hasta ile \%13,2 olarak gerçekleşti. İstatistiksel olarak hesaplanan ROC eğrisinin altında kalan alan EuroSCORE sisteminde 0,712, STS sisteminde 0,727 olarak bulundu. STS için morbiditeyi tahmin etmede ROC eğrisi kullanılarak hesaplandığında ROC eğrisinin altında kalan alan inme için 0,615, enfeksiyon için 0,562, reoperasyon için 0,421 olarak hesapland1. Sadece böbrek yetmezliği için 0,721 olarak ölçüldü.

Tablo 1. Olguların Demografik verileri

\begin{tabular}{lcc}
\hline & Sayı-Ortalama & $\begin{array}{c}\% \text { (minimum- } \\
\text { maksimum) }\end{array}$ \\
\hline Yaş & $60,56 \pm 9,6$ & $36-87$ \\
Cinsiyet & 119 & 65,4 \\
$\quad$ Erkek & 63 & 34,6 \\
Kadın & $26,2 \pm 3,9$ & $18,8-39,2$ \\
VKI & $47,4 \pm 6,4$ & $20-65$ \\
Ortalama EF & 152 & \\
NYHA & 20 & 83,5 \\
Klas II & 10 & 11 \\
Klas III & 53 & 5,5 \\
Klas IV & 84 & 29,1 \\
DM & 2 & 46,2 \\
HT & 12 & 1,1 \\
PAH & 77 & 6,6 \\
KOAH & 4 & 42,3 \\
Sigara & 2 & 2,2 \\
SVO & 95 & 1,1 \\
Renal disfonksiyon & 52,2 \\
Dislipidemi & & \\
\hline & &
\end{tabular}

VKI: Vücut Kitle indeksi, EF: Ejeksiyon Fraksiyonu, NHYA: New York Heart Association, DM: Diyabetes Mellitus HT: Hipertansiyon, PAH: Periferik Arter Hastalığı, KOAH: Kro- nik Obstrüktif Akciğer Hastalığı, SVO: Serebrovasküler Olay

Tablo 2. Operatif Veriler

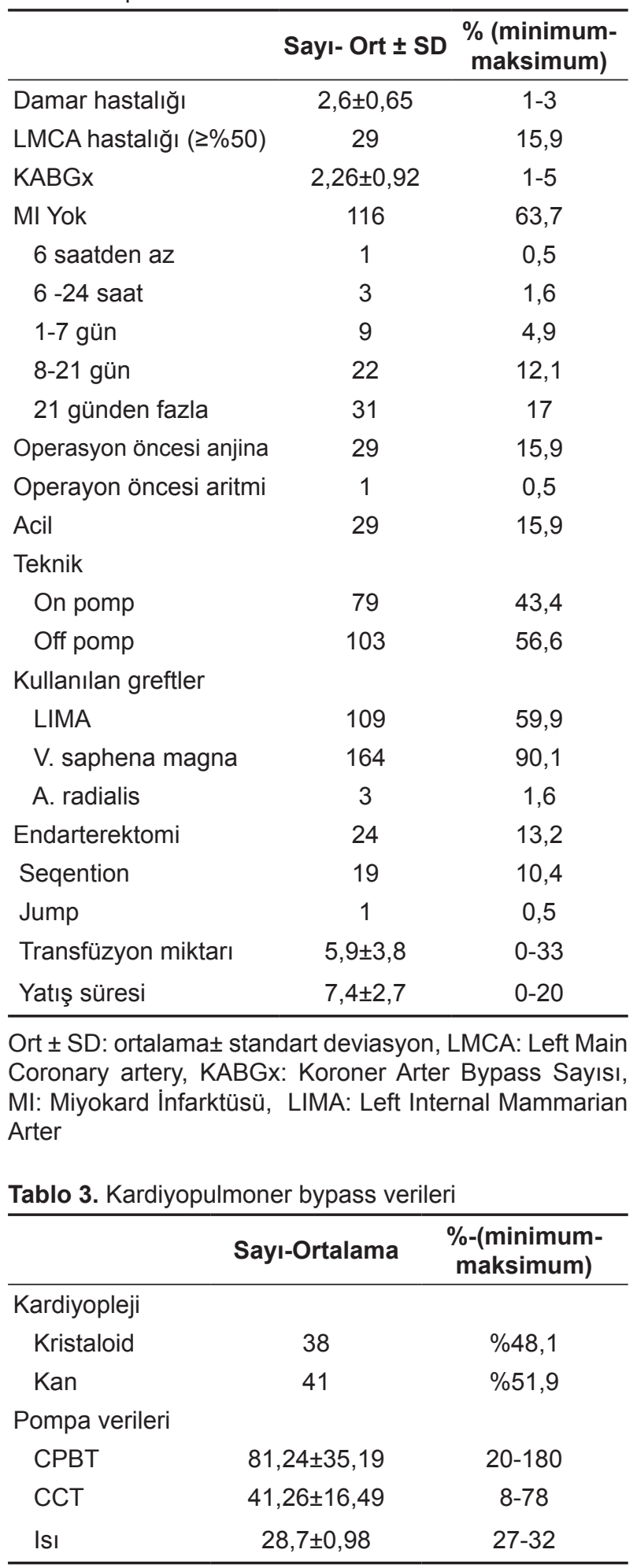

CPBT: Cardiyopulmonary Bypass Time, CCT: Cross Clamp Time 
Tablo 4. Postoperatif morbidite

\begin{tabular}{lcc}
\hline & Sayı & $\%$ \\
\hline Düşük kardiyak debi & 28 & 15,4 \\
Aritmi & 32 & 17,6 \\
Enfeksiyon & 7 & 3,8 \\
Revizyon & 6 & 3,3 \\
SVO & 10 & 5,5 \\
Böbrek yetmezliği & 1 & 0,5 \\
\hline
\end{tabular}

SVO: Serebrovasküler Olay

Tablo 5. Eksitus olan ve olmayan hastalarda EuroSCORE, STS, yaş ve EF karşılaştırması

\begin{tabular}{lccc}
\hline & $\begin{array}{c}\text { Eksitus var } \\
(\mathbf{n = 2 4 )}\end{array}$ & $\begin{array}{c}\text { Eksitus yok } \\
(\mathbf{n}=\mathbf{1 5 8 )}\end{array}$ & p değeri \\
\hline Lojistik EuroSCORE & $7,15 \pm 6,22$ & $4,34 \pm 4,69$ & 0,001 \\
Yaş & $64,5 \pm 8,12$ & $59,97 \pm 9,79$ & 0,027 \\
EF & $45,62 \pm 6,13$ & $47,75 \pm 6,44$ & 0,064 \\
STS mortalite & $2,18 \pm 2,3$ & $1,02 \pm 1,07$ & 0,001 \\
\hline
\end{tabular}

EF: Ejeksiyon Fraksiyonu, STS: Society of Thoracic Surgeon

\section{TARTIŞMA}

Sağlık kuruluşlarının temel amacı hastalarına kaliteli hizmet verip yüksek hasta memnuniyeti sağlamaktır. Fakat bu memnuniyet derecesi göreceli bir kavram olup ülkeler arasında ve her ülkenin sosyoekonomik durumuna göre farkl1l1klar göstermektedir. $\mathrm{Bu}$ amaçla öngörülebilir risklerin belirlenmesi önemlidir. İdeal risk değerlendirmeleri; belli bir hastalık grubuna göre değil hasta bazlı sonuçları doğru tahmin etmeli pratik, ucuz ve objektif olmalidir.

Kalp hastalarının tedavisinde hangi tedavi yönteminin seçileceğinde kanıta dayalı protokoller rehber olmaktadır. Bu tedavi protokollerinde kararı belirleyen en önemli faktör, seçilen yöntemin hastaya getireceği yaşama şans1, diğer bir deyişle mortalite riski olmaktadır. Mortalite riski ne kadar düşükse, o yöntemin tercih edilmesi o ölçüde rasyonel olacaktır. Kalp cerrahisinde görülen tüm ilerlemelere rağmen, koroner kalp ameliyatları sonrası görülen mortalite ve morbidite günümüzde de önemli bir sorun olarak karşımıza çıkmaktadır. 1970 öncesi yaklaşı 103 civarında olan koroner cerrahisi sonras1 mortalite, 1980'li yılların başında \%0.4-0.5'e kadar indirilebilmiştir. Bu yıllardan sonra ise mortalitede bir artış izlenmeye başlanmış ve \%1,5-2 ci- varında bir değere çıkmıştır. PTCA ve diğer invaziv girişimlerdeki ilerlemenin mortalitedeki bu artışta rolü büyüktür. Bunun yanında koroner reoperasyon ameliyatlarının giderek standart cerrahi içinde daha büyük oran tutması da bu sonuçta etkendir [5]. EuroSCORE risk belirleme sistemi, 19030 hastada prospektif olarak yapılan ve beklenen mortaliteyi öngören en yeni ve en yaygın kullanılan skorlama sistemlerinden biridir [6]. Geissler ve ark. EuroSCORE ile daha önce geliştirilen Parsonet, Cleveland clinic, Ontario, French ve Pons skorlama sistemlerini karş1laştırmış ve mortalite öngörüsü için en iyi sistemin EuroSCORE olduğunu belirtmişlerdir [4]. Yine yapılan çeşitli ulusal çalışmalarda EuroSCORE sisteminin, ülkemiz hasta profiline uygun ve mortalite öngörüsünde yeterli bir sistem olduğu vurgulanmıştır [7-9].

STS risk belirleme sistemi, 1994 y1lında geliştirilmiştir [10]. Daha çok kuzey Amerika'da yaygıın olarak kullanılmaktadır. STS veritabanı geliştirildikten sonra toplam 1,5 milyon kayıta ulaşmıştır. İzole koroner bypass olgular1 505.645'tir. Bu sistem, beklenen mortalite yanında major morbiditeler hakkında da öngörülerde bulunmaktadır [11].

Yaşlı hasta grubu, özellikle 65 yaş ve üstü hasta grubunda; sol ana koroner arter hastalığı, çoklu damar hastalığ 1 , LV disfonksiyonu ve ek kapak patolojisi riski arttırmaktadır. Ayrıca KOAH, PAH ve böbrek yetmezliği ek olarak mortalite artışı üzerine etkendir [12-14]. Çalışmamızda yaş arttıkça mortalitenin arttığ 1 gözlendi. Ancak cinsiyetin mortalite üzerine etkisinin olmadığı görüldü.

Sol ventrikül fonksiyonu erken ve geç dönem mortaliteyi belirleyen önemli bir prediktördür. $\mathrm{Bu}$ hasta grubu yaşam kalitesini artırma ve yaşam süresini uzatma amaciyla opere edilmelidir [15]. Çalışmamızda EF artması mortaliteyi azalttığı buna karşın düşük fonksiyonel kapasitenin mortaliteyi anlamlı olarak arttı̆g 1 tespit edildi. On yıllık yap1lan çalışmada 3 damar hastalığı olanlarda medikal ve cerrahi tedavi sonuçları benzer çıkmış olmasına rağmen; proksimal LAD lezyonu olan ve düşük LV fonksiyonu olan hastalar cerrahiden fayda gördüğü gösterilmiştir [16-18]. Çalışmamızda hastalıklı damar sayısı artıkça mortalite artmakta, fakat koroner arter bypass sayısının artması mortaliteyi arttırmamaktadır. 
Sol ana koroner hastalığında cerrahi tedavi medikal tedaviye göre anlamlı derecede üstündür. Benzer şekilde sol ana koroner ekivalanı olan proksimal LAD ve Cx hastalığında da aynı sonuçlar elde edilmiştir $[19,20]$. Çalışmamızda da ana koroner hastalığının mortalite üzerine etkisinin olmadığı sonucu literatür ile uyumludur.

Çalışan kalpte cerrahi uygulamalarıyla vücut dışı dolaşıma bağlı olumsuz etkilerin giderilmesi, solunum işlevleri ve mekanik solunum desteği gereksinimi konusunda avantaj sağlamaktadır. Ek olarak nörolojik yan etkilerinin daha az olmas1, pulmoner ve renal sistem üzerine daha az patolojik yan etkilerinin olması yanında, bu yönteminde kendi içinde riskleri vardır [21]. Mortaliteye etki eden HT, DM, PAH, KOAH, SVH, sigara, dislipidemi, geçirilmiş Mİ, preoperatif aritmi faktörlerinin çalışmamızda direk mortaliteyi etkilememiş olması bu hasta grubunda atan kalpte koroner cerrahinin tercih edilmesinden kaynaklandığı düşünülmüştür.

Çalışmamızda kullanılan ROC eğrisi her iki skorlama sistemi için ayırıcı gücünün yeterli olduğu görülmüştür. Vanagas ve arkadaşları tarafından yapilan ve EuroSCORE, Parsonnet, Ontario ve Quality Measurement and Management Initiative karşılaştırılmış sonuçlarında ölüm gelişen hastaları yüksek risk grubunda olduğu tespit edilmiştir. Mortaliteyi tahmin etmede Parsonnet ve Quality Measurement and Management Initiative ve EuroSCORE daha değerli çıkmış fakat en değerli olanın QMMI olduğu izlenmiştir [22]. Mandel ve arkadaşlarının EuroSCORE ve STS değerlendirmelerinde her iki skorlama sisteminin geliştirilmesi gerektiği fakat şu an için cerrahlar için vazgeçilmez olduğu bildirilmiştir [23]. Çin Halk Cumhuriyetin 'de 35 kalp merkezinde 9248 hastanın EuroSCORE ile değerlendirilmesinde koroner bypass cerrahisi için sonuçların tahmin etmede kullanılamayacağ 1 ve kendi ırkları için ayrı bir skorlama sistemine gerek olduğunu savunmaktadırlar [24].

Ülkemiz hasta grubu üzerinde yapılan EuroSCORE çalışmalarından biri Karabulut ve arkadaşlarının 2001 yılında yaptıkları çalışmadır. Bu çalışmada sadece mortalite değerleri incelenmiş olup EuroSCORE 'un belirlemiş olduğu mortalite oranlarına göre gerçekleşen mortalitenin daha düşük düzeyde olduğu belirtilmiştir [25].Buna karşın; Okutan ve arkadaşlarının 2002 yılında 319 hastanın verileri ile yapılan retrospektif çalışmada istatistiksel fark saptanmamıştır ve ROC değeri 0,71 olarak bulunarak EuroSCORE un kolay uygulanabilir sistem olduğu vurgulanmıştır [7]. EuroSCORE ile STS skorlamasının karşılaştırıldığ demir ve arkadaşları ROC eğrisi ile değerlendirmelerinin sonucunda ROC eğrisinin altında kalan alan, EuroSCORE sisteminde 0.83, STS sisteminde 0.82 olarak bulunmuştur ( $p>0.05$ ). EuroSCORE sisteminin kullanılacağ 1 ve STS 'nin morbiditeyi vermesi açısından anlamlı bulunmuştur [26]. Bizim çalışmamızda STS skorlama sisteminin morbiditeyi verdiği fakat ROC değerlendirilmesine göre sadece böbrek yetmezliğini tahmin etmede anlamlı olduğu bulunmuştur. İki sistem arasında farklılıklar STS 'de irk faktörünün olmas1, EuroSCORE 'de pulmoner hipertansiyon, koroner bypass dışında ek kalp cerrahisi, göğüs cerrahi ve Post-MI VSD olması bulunmaktadır. STS sadece koroner ve ek kapak ameliyatı olanlarda ölçüldügünden eksiklik olarak görülmüştür.

EuroSCORE çalışmamızda 30 günlük mortalite tahmini için değerlidir. STS ülkemizde mortaliteyi tahmin etmekte kullanılmaktadır. Morbidite için çalışmaların sonucu beklenmelidir. Her iki skorlama da Avrupa ve Amerika toplumlarının verileri olduğu için ülkemize uygun benzer skorlama sistemlerine ihtiyaç duyulmaktadır. Ülkemize özgü devam eden ve yeni yapılacak çalışmaların sonuçlarına göre risk hesaplaması yapılması Türkiye' de yaşayan koroner hastaların veri tabanını değerlendirmede daha uygun olacağ d düşüncesindeyiz.

Çalışmamız 10. Kardiyoloji ve Kardiyovasküler Cerrahide Yenilikler Kongresi'nin (KKVC) 13 -16 Mart 2014 tarihinde Antalya'da sözlü poster olarak sunulmuştur.

\section{KAYNAKLAR}

1. Ferraris V, Edwards F, Shahian D, Ferraris S. Risk Stratification and Comorbidity. Cohn LH, ed. Cardiac Surgery in the Adult. New York: McGraw-Hill, 2008;199-246.

2. Parsonnet V, Dean D, Bernstein AD. A method of uniform stratification of risk factor evaluating the results of surgery in acquired adult heart disease. Circulation. 1989;79:3-12.

3. Higgins TL, Estafanous FG, Loop FD, et al. Stratification of morbidity and mortality outcome by preoperative risk factors in coronary artery bypass patients. J Am Med Assoc 1992;267:2344-48. 
4. Geissler HJ, Hölzl P, Sacha M, et al. Risk stratification in heart surgery: Comparison of six score systems. Eur J Cardiothorac Surg. 2000;17:400-6.

5. Hamulu A, Özbaran M, Atay Y, Posacıŏlu H. Koroner Bypass Ameliyatında Mortalite ve Morbiditeye Etki Eden Risk Faktörlerinin Belirlenmesi ve Değerlendirilmesi. Türk Göğüs Kalp Damar Cer Derg 1995;3:245-52.

6. Nashef SAM, Roques F, Michel P, et al. European system for cardiac operative risk evaluation (EuroSCORE). Eur J Cardiothorac Surg 1999;16:9-13.

7. Okutan H, Yavuz T, Peker O, et al. Kliniğimizde ameliyat olan hastalarda Euroscore (European System for Cardiac Operative Risk Evaluation) risk skorlama sistemine göre sonuçlar. Türk Göğüs Kalp Damar Cer Derg 2002;10:201-5.

8. Kaplan M, Kut MS, Çimen S, Demirtaş MM. EuroSCORE (European System for Cardiac Operative Risk Evaluation) risk skorlama sisteminin ülkemiz hasta profilinde uygulanabilirliğinin araştırılması. Türk Gögüs Kalp Damar Cer Derg 2003;11:147-58.

9. Soyal T, Özeren M, Kar M, et al. Koroner arter bypass reoperasyon adaylarında mortalite ve morbiditenin EuroSCORE ile retrospektif analizi. Türk Göğüs Kalp Damar Cer Derg 2004; $12: 241-5$.

10. Clark RE. The Society of Thoracic Surgeons National Database status report. Ann Thorac Surg 1994;57:20-6.

11. Shroyer ALW, Coombs LP, Peterson ED, et al. The Society of Thoracic Surgeons: 30-Day Operative Mortality and Morbidity Risk Models. Ann Thorac Surg 2003;75:185665 .

12. Acinapura AJ, Jacobowitz IJ, Kramer MD, et al. Demographic changes in coronary artery bypass surgery and its effect on mortality and morbidity. Eur J Cardiothorac Surg 1990;4:175-81.

13. Ivanov J, Weisel RD, David TE, Naylor CD. Fifteen-year trends in risk severity and operative mortality in elderly patients undergoing coronary artery bypass graft surgery. Circulation 1998;97:673-80.

14. McGrath LB, Laub GW, Graf D, Gonzalez-Lavin L. Hospital death on a cardiac surgical service: negative influence of chang ing practice patterns. Ann Thorac Surg 1990;49:4102.

15. Baker DW, Jones R, Hodges J, et al. Management of heart failure, III: the role of revascularization in the treatment of patients with moderate or severe left ventricular systolic dysfunction. JAMA 1994;272:1528-34.
16. Varnauskas E. Twelve-year follow-up of survival in the randomized European Coronary Surgery Study. N Engl J Med 1988;319:332-7.

17. Yusuf S, Zucker D, Peduzzi P, et al. Effect of coronary artery bypass graft surgery on survival: overview of 10year results from randomised trials by the Coronary Artery Bypass Graft Surgery Trialists Collaboration. Lancet 1994;344:563-70.

18. Rogers WJ, Coggin CJ, Gersh BJ, et al. Ten-year follow-up of quality of life in patients randomized to receive medical therapy or coronary artery bypass graft surgery. The Coronary Artery Surgery Study (CASS). Circulation 1990; 82: 1647-58.

19. Caracciolo EA, Davis KB, Sopko G, et al. Comparison of surgical and medical group survival in patients with left main equivalent coronary artery disease: long-term CASS experience. Circulation 1995;91:2335-44.

20. Chaitman BR, Fisher LD, Bourassa MG, et al. Effect of coronary bypass surgery on survival patterns in subsets of patients with left main coronary artery disease: report of the Collaborative Study in Coronary Artery Surgery (CASS). Am J Cardiol 1981;48:765-77.

21. Wijeysundera DN, Beattie WS, Djaiani G, et al. Cusimano Off-Pump Coronary Artery Surgery for Reducing Mortality and Morbidity: Meta-Analysis of Randomized and Observational Studies J. Am. Coll. Cardiol. 2005;46:872-82.

22. Vanagas G, Kinduris1 Š, Leveckytè A. Comparison of various score systems for risk stratification in heart surgery. Medicina 2003;39:739-44.

23. Mandel M, Simchen ES, Gurevich YZ. Does the EuroSCORE perform well on the STS population? Eur J Cardiothoracic Surg 2003;24:334-7.

24. Zheng Z, Li Y, Zhang S, Hu S. The Chinese Coronary Artery Bypass Grafting Registry Study: how well does the EuroSCORE predict operative risk for Chinese population. Eur J Cardio-thoracic Surg 2009;35:54-61.

25. Karabulut H,Toraman F, Dağdelen S, ve ark. EuroSCORE (European System for Cardiac Operative Risk Evaluation) Risk Skorlama Sistemi Gerçekçi mi? Türk Kardiyol Dern Arş 2001;29:364-67.

26. Kandemir Ö, Büyükateş M, Turan SA, ve ark. Koroner Bypass Cerrahisinde EuroSCORE VE STS (The Society Of Thoracıc Surgeons) Risk Skorlama Yöntemlerinin Karş1laştırılması. Türk Göğüs Kalp Damar Cer Derg 2007;18:7880. 